\title{
Strabismus in the north of Mexico: clinical characteristics in a pediatric population at public and private health institutions
}

\section{Estrabismo en el norte de México: características clínicas en pacientes pediátricos de instituciones de salud públicas y privadas}

\author{
Juan Homar Páez-Garza ${ }^{1,2 *}$, Andrea Rangel-Padilla ${ }^{1,2}$, Sara González-Godínez ${ }^{1,2}$ and \\ Sylvia de la Rosa-Pacheco ${ }^{1,3}$ \\ ${ }^{1}$ Tecnológico de Monterrey, School of Medicine and Health Sciences, Monterrey; ${ }^{2}$ Institute of Ophthalmology and Visual Sciences, Hospital \\ Zambrano Hellion, San Pedro Garza García; ${ }^{3}$ TecSalud National Clinical Research Directorate, Hospital Zambrano Hellion, San Pedro Garza García. \\ N.L., Mexico
}

\begin{abstract}
Introduction: Strabismus is one of the main causes of visual disability. Most cases are reversible with appropriate treatment; however, several factors can influence its diagnosis. Objective: To describe the demographic and clinical characteristics of strabismus in children from northern Mexico. Material and methods: We carried out a study to analyze the characteristics associated with strabismus in pediatric patients of a private hospital (Centro Médico Zambrano Hellion [CMZH]) and a primary care center (CeSI). Results: One-hundred and eighty nine patients were included. Median age at strabismus onset was 11 months, with a median age of 3.3 years when attending the clinic for the $1^{\text {st }}$ time, and the average time to seek medical care was of 13 months. Age of onset was higher in CMZH. However, the time it took patients to seek medical care was higher in CeSI ( $p<0.001)$. The prevalence of amblyopia was significantly higher in CeSI $(p=0.007)$. Conclusions: This is the first study that describes the clinical and demographic characteristics associated with a diagnosis of strabismus in northern Mexico. Our results agree with other studies in Mexican and American populations. By analyzing the socioeconomic characteristics of the population, we conclude that it is of utmost importance to ensure that low-income population has access to specialized health services in order to receive an appropriate treatment.
\end{abstract}

Key words: Strabismus. Diagnosis. Children. Demographic. Socioeconomic.

\section{Resumen}

Introducción: El estrabismo es una de las principales causas de discapacidad visual. Con el tratamiento oportuno, la mayoría de los casos son reversibles; sin embargo, diversos factores pueden influir en su diagnóstico. Objetivo: Describir las características demográficas y clínicas del estrabismo en niños del norte de México. Material y métodos: Se realizó un estudio para analizar las características asociadas a estrabismo en pacientes pediátricos de un hospital privado (Centro Médico Zambrano Hellion [CMZH]) y un centro de salud integral (CeSI). Resultados: Se incluyeron 189 pacientes. La mediana de edad al iniciar el estrabismo fue de 11 meses, la mediana de edad de la primera consulta fue de 3.3 años, y el

Correspondence:

*Juan Homar Páez-Garza

Av. Batallón de San Patricio, 112 Col.

Real San Agustin

Date of reception: 31-07-2019

Date of acceptance: 06-12-2019

DOI: 10.24875/RMOE.M20000111
Available online: $04-05-2020$ Rev Mex Oftalmol (Eng). 2020;94(3):99-104 www.rmo.com.mx 
tiempo que tomó en acudir a la consulta fue de 13 meses. La edad de inicio del padecimiento fue mayor en el CMZH. Sin embargo, el tiempo que los pacientes tardaron en buscar atención fue mayor en el CeSI $(p<0.001)$. La prevalencia de ambliopía fue significativamente mayor en el CeSI $(p=0.007)$. Conclusiones: Este es el primer estudio que describe las características clínicas y demográficas asociadas al diagnóstico de estrabismo en el norte de México. Nuestros resultados concuerdan con estudios realizados en la población mexicana y norteamericana. Al analizar las características socioeconómicas de la población concluimos que es de suma importancia garantizar el acceso a servicios de salud a población de escasos recursos para brindar un tratamiento oportuno.

Palabras clave: Estrabismo. Diagnóstico. Niños. Demografía. Socioeconómico.

\section{Introduction}

Strabismus is defined as an ocular misalignment caused by binocular vision abnormalities or neuromuscular alterations of ocular motility control ${ }^{1}$. In children it affects visual development by preventing binocular vision, since there is a fixative eye and a deviant eye, so the brain suppresses the signal from the deviant eye as a mechanism to prevent diplopia. The suppression favors the development of amblyopia, a developmental disorder of the central nervous system that occurs in the first years of life and results from abnormal image processing, which leads to a decrease in visual acuity.

Strabismus is a disease that affects between 2 and $4 \%$ of children ${ }^{2}$. It is one of the main causes of amblyopia, the most frequent treatable cause of decreased visual acuity in children ${ }^{3}$. Strabismus treatment is one of the interventions with the greatest benefits in ophthalmology due to the irreversible long-term consequences if adequate treatment is not received ${ }^{4-8}$. With the appropriate treatment, which generally consists of optical and/or surgical correction, coupled with visual rehabilitation with ocular occlusion or optical penalty of the dominant eye, most cases of amblyopia are reversible, reducing the risk of future visual disability ${ }^{4}$.

There are various classifications of strabismus ${ }^{9-12}$. The American Academy of Ophthalmology (AAO) classifies the different types of strabismus into endodeviations, exodeviations, and vertical deviations, as well as special forms of strabismus ${ }^{13}$.

The most frequent types of strabismus vary according to the population studied. It has been observed that various sociodemographic factors can influence its diagnosis, such as place of residence, economic income and access to specialized health services, and timely diagnosis is more likely in populations with high socioeconomic status and less likely in populations that suffer financial shortages ${ }^{4,14,15}$. The condition itself, family environment and the health care system are factors that can delay the diagnosis of strabismus and, therefore, treatment ${ }^{4}$.

\section{Objective}

Currently, there are few data on the most frequent forms of strabismus in Mexico, so the objective of our study is to describe the demographic and clinical characteristics of strabismus diagnosed in children in the northern region of Mexico ${ }^{10-12}$.

As secondary objectives, the differences between a public institution and a private care center will be analyzed, as well as the factors that may influence the diagnosis of strabismus.

\section{Material and methods}

A descriptive study of consecutive cases of strabismus was carried out in two reference sites in the northeast region of Mexico, with the aim of evaluating the clinical and demographic characteristics of pediatric patients diagnosed with strabismus. This study was approved by the Ethics Committee of the Tecnológico de Monterrey School of Medicine.

Patients who attended two specialized reference sites were included: the Institute of Ophthalmology and Visual Sciences of the Centro Médico Zambrano Hellion (CMZH), a private hospital attended by patients of high socioeconomic status, and the Ophthalmology Clinic of the Centro de Salud Integral (CeSI) of the Fundación TEC Salud, a public medical center attended by low-income patients. The records of patients under 16 years of age examined from April 1, 2015, whose reason for consultation was strabismus, were retrospectively reviewed, until 100 patients were completed in each site. The following clinical data were collected: sex, age (in months) at the first consultation in the clinic, age (in months) at strabismus onset, time (in months) to seek medical attention, type of strabismus diagnosed, person who identified the condition, presence of amblyopia and type of amblyopia (if present).

Visual acuity measurement was performed in a monocular standardized way using preferential visual acuity charts at $40 \mathrm{~cm}$ in preverbal children and optotype 
Table 1. Clinical and epidemiological characteristics by site

\begin{tabular}{|c|c|c|c|c|}
\hline Clinical and epidemiological characteristics & Total $n=189(100 \%)$ & CMZH (n = 95) & CeSi $(n=94)$ & p \\
\hline Female, n (\%) & $94(49.7)$ & $46(48.4)$ & $48(51.1)$ & $0.547^{*}$ \\
\hline $\begin{array}{l}\text { Age at first consultation } \\
\text { Median in months (min.-max.) }\end{array}$ & $39.5(6-192)$ & $35(6-192)$ & $45(8-184)$ & $0.259^{\dagger}$ \\
\hline $\begin{array}{l}\text { Age at strabismus onset } \\
\text { Median in months (min.-max.) }\end{array}$ & $11(0-189)$ & $17(0-189)$ & $6(0-172)$ & $0.067^{\dagger}$ \\
\hline $\begin{array}{l}\text { Time to seek care } \\
\text { Median in months (min.-max.) }\end{array}$ & $13(0-168)$ & $11(0-144)$ & $22(1-168)$ & $0.001^{\dagger}$ \\
\hline $\begin{array}{l}\text { Strabismus type by category, } \mathrm{n}(\%) \\
\text { Esotropia } \\
\text { Exotropia } \\
\text { Vertical strabismus } \\
\text { Others }\end{array}$ & $\begin{array}{c}99(52.4) \\
65(34.4) \\
4(2.1) \\
21(11.1)\end{array}$ & $\begin{array}{c}44(46.3) \\
38(40) \\
2(2.1) \\
11(11.6)\end{array}$ & $\begin{array}{c}55(58.5) \\
27(28.7) \\
2(2.1) \\
10(10.6)\end{array}$ & $0.373^{*}$ \\
\hline
\end{tabular}

drawings (LEA) or letters (Snellen) charts at $6 \mathrm{~m}$ in verbal children. Those cases in which best-corrected visual acuity showed a difference greater than or equal to 2 lines between both eyes or a difference equal to or greater than 2 eighths (in the case of preferential visual acuity charts), were categorized as amblyopia.

To simplify the analysis, strabismus cases were categorized into 4 types: esotropia, exotropia, vertical strabismus, and others. Esotropias included accommodative, partially accommodative, infantile and others. Exotropias included intermittent, basic constant and sensory; vertical strabismus included dissociated vertical deviation, hyperfunction of the inferior oblique muscle and double elevator palsy. Finally, other types included dissociated horizontal deviation, Duane syndrome, Brown syndrome, and cranial nerves paralysis or paresis.

The data was encoded to protect the identity of the patients and analyzed using SPSS Statistics for Windows, Version 25.0 IBM Corp. Descriptive statistics were used, including frequencies and percentages, means, medians, standard deviation, minimum and maximum according to the distribution of the variables. The results were analyzed overall and by site. To assess secondary objectives, clinical data were compared according to the site where the information was obtained. Chi square test was used for frequency comparisons and Mann Whitney $U$ test for median comparisons, according to the distribution of continuous variables. The age distribution of the patients and its correlation with the type of strabismus was analyzed using the Kruskall-Wallis test for independent samples.

\section{Results}

There were a total of 201 charts reviewed. Twelve cases were eliminated, 11 due to a diagnosis of consecutive exotropia and one due to missing information. A total of 189 subjects were included in the analysis, 95 from the $\mathrm{CMZH}$ and 94 from the CeSI.

There was a similar sex distribution in both sites, with $49.7 \%$ females $(48.4 \%$ in the $\mathrm{CMZH}$ and $51.1 \%$ in the CeSI). The median age reported at strabismus onset was 11 months (0-189 months). Median age when attending the consultation for the first time was 39.5 months or 3.3 years (6 months-16 years). The time to seek consultation was of 13 months (0-14 years); however, the time to attend was longer in the CeSI population (median of 22 months) compared to the CMZH (11 months) (Table 1).

The most prevalent type of strabismus in this study was esotropia in both sites (44 patients in the CMZH and 55 in the CeSI), followed by exotropia (38 and 27 subjects, respectively) (Table 1). The most frequent specific types of strabismus in each site were intermittent exotropia in the $\mathrm{CMZH}(31.6 \%)$ and infantile esotropia in the CeSI (37.2\%) (Fig. 1).

The people who most frequently detected strabismus for the first time were the mother $(50.8 \%)$ and both parents $(20.6 \%)$, followed by other family members (9\%) and healthcare personnel (6.9\%) (Table 2).

There were 45 subjects (23.8\%) with some degree of amblyopia, and this was more prevalent in the CeSI (31 patients). In both centers, the most common types of amblyopia were secondary to strabismus, in a total of 29 subjects (15.3\%), and sensory, in 6 subjects (3.2\%), and 


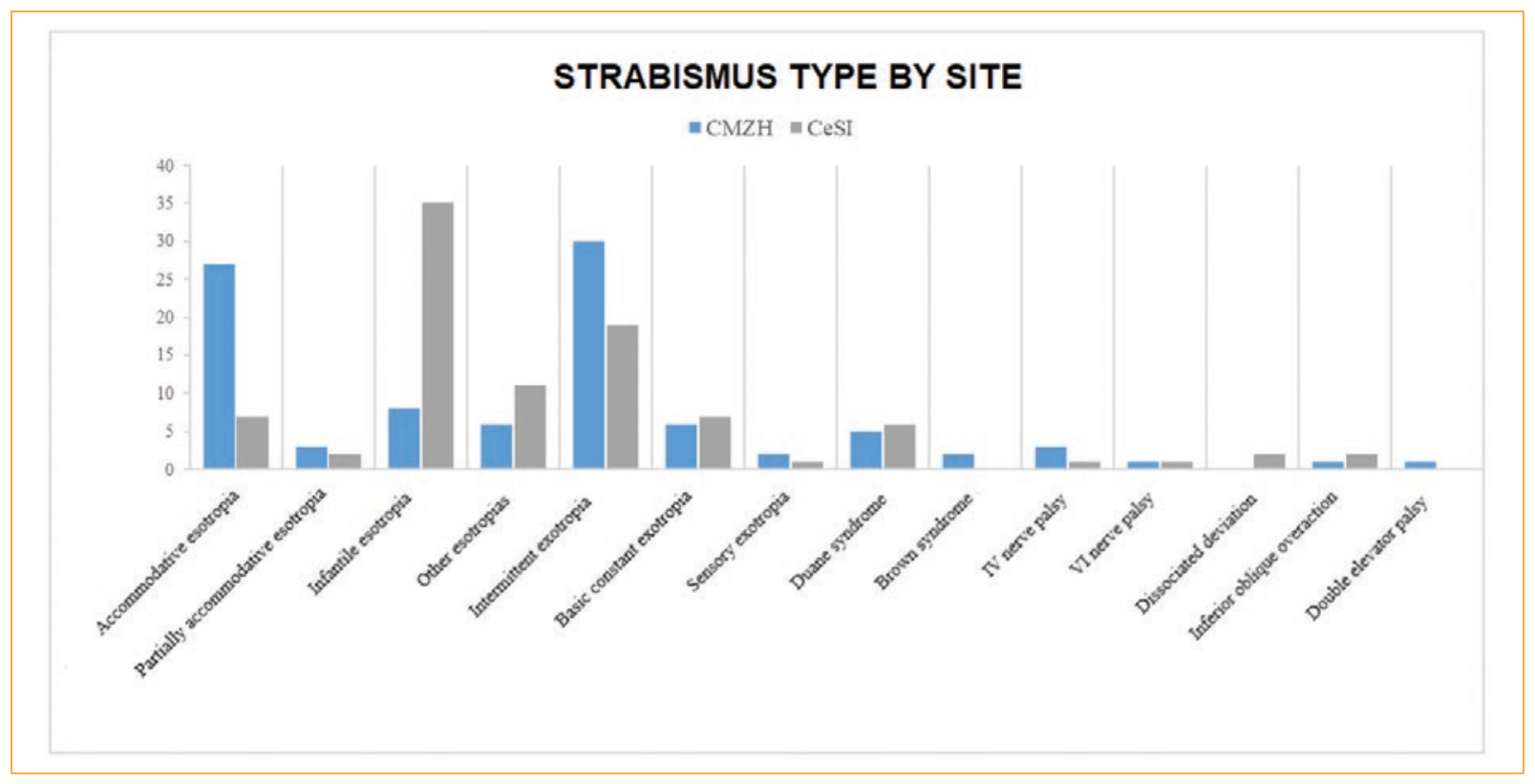

Figure 1. Strabismus type by site. CeSi: Centro de Salud Integral; CMZH: Centro Médico Zambrano Hellion.

both were more prevalent in the CeSI (17 with strabismic amblyopia and 6 with sensory amblyopia) (Table 3).

The described characteristics were compared between sites as an exploratory analysis.

A difference was observed regarding age of onset of the disease, being higher in the CMZH (17 months) compared to the CeSI (6 months), without being statistically significant $(p=0.067)$. However, the time to seek medical attention was statistically longer in the CeSI (22 months) compared to the CMZH (11 months) $(p=0.001)$. We observed a similar distribution of the types of strabismus diagnosed in both sites $(p=0.373)$ (Table 1).

The time it took to seek medical attention did not differ significantly between the different types of strabismus ( $p=0.584)$. However, the age at first consultation was lower for esotropia (30.5 months) and higher for exotropia (48 months) $(p=0.005)$. Similarly, the age at disease onset differed significantly between the different types of strabismus $(p=0.023)$, being lower in other types (6 months) and higher in vertical strabismus (26.5 months) (Table 4).

Although a correlation was observed between the site and the person who detected the condition, the condition was most commonly detected by the mother in both sites (Table 2).

Amblyopia prevalence was significantly higher in $\mathrm{CeSI}$ $(p=0.007)$. Although it was observed that the types of amblyopia differed between sites $(p=0.028)$, strabismic amblyopia was more prevalent in both sites (Table 3).
Table 2. Strabismus detection by site

\begin{tabular}{|c|c|c|c|c|}
\hline $\begin{array}{l}\text { Person who } \\
\text { identified the } \\
\text { strabismus, n (\%) }\end{array}$ & $\begin{array}{l}\text { Total } \\
n=189 \\
(100 \%)\end{array}$ & $\begin{array}{c}\text { CMZH } \\
\text { (n = 95) }\end{array}$ & $\begin{array}{c}\text { CeSi } \\
(\mathbf{n}=94)\end{array}$ & p \\
\hline Mother & $96(50.8)$ & $42(44.2)$ & $54(57.4)$ & \multirow[t]{7}{*}{$0.026^{*}$} \\
\hline Father & $8(4.2)$ & $5(5.3)$ & $3(3.2)$ & \\
\hline Both & $39(20.6)$ & $28(29.5)$ & $11(11.7)$ & \\
\hline Healthcare personnel & $13(6.9)$ & $5(5.3)$ & $8(8.5)$ & \\
\hline $\begin{array}{l}\text { Other (family member, } \\
\text { teacher, etc.) }\end{array}$ & 17 (9) & $5(5.3)$ & $12(12.8)$ & \\
\hline Unknown & $12(6.3)$ & $8(8.4)$ & $4(4.3)$ & \\
\hline Patient & $4(2.1)$ & $2(2.1)$ & $2(2.1)$ & \\
\hline
\end{tabular}

${ }^{*}$ Chi square

CeSi: Centro de Salud Integral; CMZH: Centro Médico Zambrano Hellion.

Table 3. Clinical features of amblyopia

\begin{tabular}{|c|c|c|c|c|}
\hline $\begin{array}{l}\text { Clinical features of } \\
\text { amblyopia }\end{array}$ & $\begin{array}{c}\text { Total } \\
n=189 \\
(100 \%)\end{array}$ & $\begin{array}{l}\text { CMZH } \\
(n=95)\end{array}$ & $\begin{array}{c}\text { CeSi } \\
(n=94)\end{array}$ & p \\
\hline Amblyopia, n (\%) & $45(23.8)$ & $14(14.7)$ & $31(33)^{*}$ & $0.007^{\dagger}$ \\
\hline $\begin{array}{l}\text { Amblyopia type, n (\%) } \\
\text { Anisometropic } \\
\text { Strabismic } \\
\text { Mixed } \\
\text { Sensory }\end{array}$ & $\begin{array}{c}4(2.1) \\
29(15.3) \\
5(2.6) \\
6(3.2)\end{array}$ & $\begin{array}{c}0 \\
12(12.6) \\
1(1.1) \\
1(1.1)\end{array}$ & $\begin{array}{c}4(4.3) \\
17(18.1) \\
4(4.3) \\
5(5.3)\end{array}$ & $0.028^{\dagger}$ \\
\hline
\end{tabular}


Table 4. Median age in months at diagnosis by strabismus type

\begin{tabular}{|l|c|c|c|c|}
\hline $\begin{array}{l}\text { Strabismus type } \\
\text { Esotropia }\end{array}$ & $\begin{array}{c}\text { Frequency } n=189 \\
(100 \%)\end{array}$ & $\begin{array}{c}\text { Age at onset } \\
(\text { min.-max.) }\end{array}$ & $\begin{array}{c}\text { Age at first consultation } \\
(\text { min.-max.) }\end{array}$ & $\begin{array}{c}\text { Attention time } \\
\text { (mín.-max.) }\end{array}$ \\
\hline Exotropia & $99(52.4)$ & $7(0-65)$ & $30.5(6-156)$ & $12(0-168)$ \\
\hline Vertical strabismus & $65(34.4)$ & $18(0-86)$ & $48(10-180)$ & $17(0-146)$ \\
\hline Others & $4(2.1)$ & $26.5(24-36)$ & $40(34-180)$ & $13.5(10-144)$ \\
\hline p-value & $21(11.1)$ & $6(0-189)$ & $42(7-192)$ & $17(1-111)$ \\
\hline
\end{tabular}

*Kruskal-Wallis test for independent samples.

\section{Discussion}

This study that evaluated a pediatric population from northern Mexico, aims to describe the clinical and demographic characteristics associated with a diagnosis of strabismus. In this study, we found that strabismus occurs with the same frequency in both sexes, consistent with other study conducted in Mexico City ${ }^{12}$.

Unlike other populations, such as Asian, where exotropia seems to be more frequent ${ }^{15}$, in this study esotropia represented the most frequent type of strabismus, and this is consistent with studies conducted in Mexican and North American populations ${ }^{10,12.14}$.

Regarding the time it took to seek specialized care, we found a difference favoring patients with higher financial resources that attended the private center (CMZH) compared to patients with limited resources (CeSI) who sought care later, a factor that influences the development of amblyopia. Studies in the USA have shown that the probability of a child being diagnosed with strabismus is associated with the characteristics of the community in which he/she resides, and that children that live in communities of low socioeconomic status are less likely to be diagnosed with strabismus compared to children living in high-income communities $^{4}$, making it extremely important to ensure that children living in less fortunate conditions have access to specialized health services to diagnose and provide adequate and timely treatment. The fact that these children are not properly diagnosed and treated could explain the high prevalence of visual impairment in adults residing in communities of low socioeconomic status 4

Differences in age of onset, first visit, and the time it took to seek medical attention may indicate that certain types of strabismus are easier to detect than others, highlighting the importance of specialized medical care including an early ocular exam, as recommended by clinical guidelines ${ }^{16}$.

Similar to what was reported in a study by Friedman, et al., we observed a high prevalence of amblyopia in our population, compared to that reported in the general population (3\%), since strabismus represents one of the main causes of amblyopia ${ }^{17}$.

The fact that in most cases the mother is the person who detects strabismus, makes us reflect on the need to spread the importance of timely detection and treatment of strabismus from primary care (which according to this study only detected $7.5 \%$ of cases), since timely detection could prevent the development of visual sequelae.

\section{Strengths and limitations}

As this was a descriptive study, it has limitations inherent to the design, including limited representativeness of the pediatric population with strabismus in northern Mexico, lack of a formal sample size estimation and the study scope. Data collection was performed retrospectively, which could affect the quality of the data.

Despite these limitations, the number of patients and data included allowed us to perform an exploratory analysis to compare the characteristics between sites. Furthermore, to the best of our knowledge, this is the first study in a pediatric population that describes the clinical and demographic characteristics associated with the diagnosis of strabismus in northern Mexico.

\section{Conflicts of interest}

The authors declare that they have no conflict of interest, since this work was conducted with their own resources. 


\section{Ethical disclosures}

Protection of human and animal subjects. The authors declare that no experiments were performed on humans or animals for this study.

Confidentiality of data. The authors declare that they have followed the protocols of their work center on the publication of patient data.

Right to privacy and informed consent. The authors declare that no patient data appear in this article.

\section{References}

1. American Academy of Ophthalmology Basic and Clinical Science Course Subcommittee. Basic and Clinical Science Course. Pediatric Ophthalmology and Strabismus: Section 6, 2016-2017. San Francisco, CA: American Academy of Ophthalmology; 2016.

2. Mohney BG, Greenberg AE, Diehl NN. Age at strabismus diagnosis in an incidence cohort of children. Am J Ophthalmol. 2007;144(3):467-9.

3. Wu C, Hunter DG. Amblyopia: diagnostic and therapeutic options. Am J Ophthalmol. 2006;141(1):175-84.

4. Ehrlich JR, Anthopolos R, Tootoo J, Andrews CA, Miranda ML, Lee PP, et al. Assessing Geographic Variation in Strabismus Diagnosis among Children Enrolled in Medicaid. Ophthalmology. 2016;123(9):2013-22.
5. Group PEDI. A comparison of atropine and patching treatments for moderate amblyopia by patient age, cause of amblyopia, depth of amblyopia, and other factors. Ophthalmology. 2003;110(8):1632-7.

6. Simons K, Preslan M. Natural history of amblyopia untreated owing to lack of compliance. Br J Ophthalmol. 1999;83(5):582-7.

7. Group. PEDI. A randomized trial of atropine vs. patching for treatment of moderate amblyopia in children. Arch Ophthalmol. 2002;120(3):268-78.

8. Campbell LR, Charney E. Factors associated with delay in diagnosis of childhood amblyopia. Pediatrics. 1991;87(2):178-85.

9. Romero-Apis D. Aspectos Básicos. Estrabismo México: Auroch. 2000:1-37.

10. Arroyo-Yllanes M. Clasificación etiopatogénica del estrabismo. Rev Mex Oftalmol. 1987;61(2):59-62.

11. Prieto-Díaz J S-DC. Esotropías. En: Estrabismo. 5.a ed. Ediciones Científicas Argentinas; 2005. p. 157-217.

12. Adán-Hurtado EE, Arroyo-Yllanes ME. Frecuencia de los diferentes tipos de estrabismo. Revista Mexicana de Oftalmología. 2009;83(6):340-8.

13. Raab EL. Basic and Clinical Science Course: Pediatric Ophthalmology and Strabismus, 2011-2012. American Academy of Ophthalmology; 2011.

14. Mohney BG. Common forms of childhood strabismus in an incidence cohort. Am J Ophthalmol. 2007;144(3):465-7.

15. Lambert SR. Are there more exotropes than esotropes in Hong Kong? Br J Ophthalmol. 2002;86(8):835-6.

16. American Academy of Ophtalmology Pediatric Ophthalmology/Strabismus Panel. Preferred Practice Pattern Guidelines. Pediatric Eye Evaluation. San Francisco, CA: American Academy of Ophthalmology, 2017.

17. Friedman DS, Repka MX, Katz J, Giordano L, Ibironke J, Hawse P, et al. Prevalence of amblyopia and strabismus in white and African American children aged 6 through 71 months the Baltimore Pediatric Eye Disease Study. Ophthalmology. 2009;116(11):2128-34.e1-2. 